\section{$016-017$ \\ Noticias y comentarios \\ PH49 - Julio 2004}

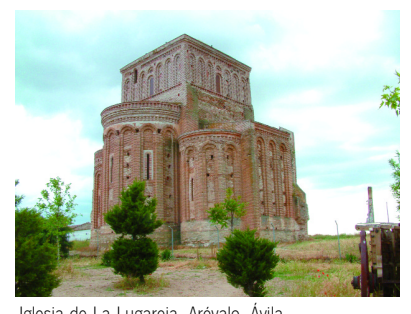

Iglesia de La Lugareja. Arévalo, Ávila

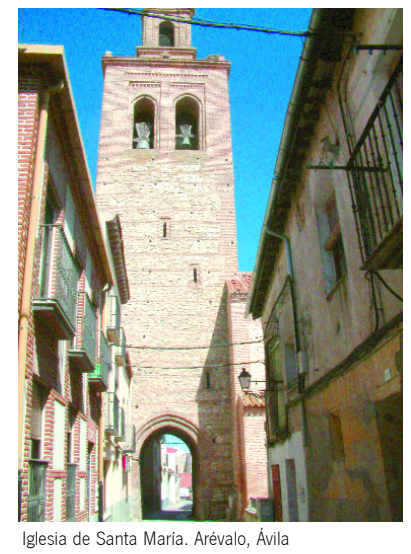

\title{
38 Lecciones de Arquitectura Española: el múdejar
}

Los días 26, 27 y 28 de marzo se celebró en Arévalo (Ávila) la trigésimo octava edición de las Lecciones de Arquitectura Española que, desde 1987, organizan la Fundación Cultural Santa Teresa y el Instituto de Arquitectura Juan de Herrera. Por sexta ocasión, las Lecciones estuvieron dedicadas a revisar el fenómeno mudéjar.

El viernes, día 26, daba comienzo el curso con una primera ponencia a cargo de Serafín de Tapia (Universidad de Salamanca), quien dedicó su intervención a los aspectos demográficos que rodearon el periodo conocido como Reconquista y Repoblación. Así, bajo el título "Mudéjares en Castilla: una biografía", De Tapia puso de manifiesto el papel jugado por esta minoría mudéjar en Castilla, aportando datos sobre su número, sus costumbres, sus oficios o las relaciones que mantuvieron con el poder cristiano. A continuación fue José Luis Gutiérrez, profesor de la Universidad Complutense de Madrid, el encargado de hablar del mudéjar al sur del Duero. En su intervención hizo hincapié en la necesidad de enfrentarnos a estos monumentos libres de corsés políticos decimonónicos (distribución provincial) y, sobre todo, de planteamientos inmovilistas e interesados. Para él, el mudéjar de esta zona, hasta que no aparezcan pruebas que lo demuestren, está todo estrechamente relacionado en formas, materiales o técnicas, haciéndose muy difícil establecer una prevalencia de unos ejemplos sobre otros, apuntando que los planos de los edificios y sus distintos elementos confirman la existencia de un grupo unitario en el sur del Duero, que no es clasificable sobre modelos foráneos y que en la zona salta sobre las cambiantes demarcaciones de los obispados medievales y sobre las fronteras de los reinos de León y Castilla.

Por la tarde, Ignacio Hernández, coordinador del Proyecto Mudéjar I, en su ponencia "Torres mudéjares de La Moraña," trató de explicar la importancia de estudiar directamente los edificios en situaciones en las que la ausencia documental es de una magnitud tan relevante como en el caso que presentó, manifestando que tal carencia puede ser compensada con un minucioso análisis del monumento. Así, el muy interesante e innovador Proyecto Mudéjar I ha posibilitado, tras la limpieza de unas torres liberadas ya de cientos de kilos de cascote y materias orgánicas, el análisis y comprensión gráfica y funcional de 25 torres del norte de Ávila. A continuación se escuchó el más que exhaustivo trabajo de investigación que Isabel López Fernández, profesora de la Universidad de Salamanca, ha llevado a cabo sobre un monumento tan singular como es La Lugareja. Exposición que tuvo su complemento necesario el día siguiente con una visita al lugar especialmente interesante además de agradecida por los asis- tentes, dadas las dificultades que siempre encierra acceder a un monumento que se encuentra en un terreno particular, por muchas declaraciones que lo amparen.

La sesión de tarde fue cerrada por José Miguel Merino de Cáceres, de la Universidad Politécnica de Madrid, dedicando su tiempo a las torres segovianas, poniendo de manifiesto su escepticismo sobre la vinculación mudéjar que se les ha atribuido. Argumentaba su opinión basándose tanto en datos cronológicos como estilísticos $\mathrm{y}$, especialmente, metrológicos.

Una de las características de estas Lecciones es la combinación de las sesiones teóricas con otras destinadas a visitas prácticas a diferentes lugares de interés. En esta ocasión, el sábado, día 27, en la sesión matutina, el casi centenar de participantes tuvo la fortuna de poder ver algunos de los testimonios más significativos del pasado arquitectónico de Cuellar, Samboal o Montuenga, acompañados por el profesor J. Antonio Ruiz Hernando (Universidad Politécnica de Madrid), quien también presentó en sus planteamientos serias dudas sobre lo conveniente 0 no de la denominación "mudéjar" para esta arquitectura.

Enrique Nuere Matauco, también de la Universidad Politécnica de Madrid, clausuró la sesión de tarde presentando el trabajo que ha realizado en la restauración de las armaduras de San Nicolás de Bari, templo en el que fue bautizada Isabel de Castilla, de Madrigal de las Altas Torres. También se refirió a la diferencia que presentan estos trabajos de carpintería según tengan fines estructurales o únicamente decorativos o a la importancia del componente étnico mudéjar en su desarrollo.

Sin bajar la intensidad que distingue a estas jornadas, la mañana del domingo se dedicó en primer lugar a realizar una visita por alguna de las torres de las iglesias de Arévalo, concretamente Santa María, San Martín y El Salvador, incluidas en el Proyecto Mudéjar I, que tiene por objetivos mejorar su estado general, su estudio, conocimiento y disfrute, asi como intentar que se conviertan en elementos motores de cierto desarrollo para la comarca.

Las sesiones académicas comenzaron con la participación de Donatella Giansante, especialista italiana en encuadernaciones, que habló de las características técnicas e influencias de un trabajo poco conocido pero notable por su calidad y resultados, aparte de referirse a la relación que por cuestiones históricas han mantenido ambos países y que facilitó la expansión de este tipo de trabajos. Rafael Manzano, de la Academia de Bellas Artes de San Fernando, ilus- 
tró al público con una brillante intervención sobre el mudéjar sevillano, resaltando el papel jugado por las iglesias rurales y poniendo una vez más de manifiesto el peso del arte hispanomusulmán en el posterior desarrollo de la arquitectura medieval hispana.

Gonzalo Borrás, uno de los autores -desde la Universidad de Zaragoza- que más ha aportado a la historiografía moderna sobre el mudéjar, dejó claras muestras de su magisterio en una intervención titulada "Las mezquitas mudéjares de Aragón: un ejemplo de aculturación", donde explicó no sólo el peso de las minorías con posterioridad a la conquista de Toledo sino cómo algunos grupos mantuvieron su culto y sus costumbres hasta el punto de construir templos de nueva planta en épocas ya bastante avanzadas. Además adelantó datos que pronto serán publicados sobre las últimas investigaciones realizadas sobre el tema.

Estas Lecciones tuvieron su broche final con la ponencia que Pedro Navascués dedicó a la arquitectura neomudéjar. En ella, el Académico de Bellas Artes de San Fernando expuso como la influencia del mudéjar y de lo islámico traspasa el ámbito medieval y se manifiesta en la arquitectura decimonónica y de principios del siglo XX en España, como un rasgo de identidad propio de la arquitectura contemporánea. Hizo un recorrido por alguno de los edificios más sin- gulares que pueden adscribirse al neomudéjar, entre otros, plazas de toros, estaciones de tren, palacios y casas de la burguesía y la nobleza española, templos o edificios realizados para la Exposición Universal de Sevilla.

Como conclusión de estas jornadas podemos destacar la importancia de la presencia musulmana en tierras peninsulares, cuya trascendencia va más allá de límites temporales o territoriales, y que este patrimonio mudéjar es esencial para comprender las manifestaciones artísticas hispanas. Que aún es mucho lo que queda por conocer de este patrimonio monumental, que en ocasiones ha sido maltratado e ignorado. Al margen de la cuestión tantas veces debatida de si existe o no un arte mudéjar, lo que es evidente es que el patrimonio artístico español no puede entenderse sin el componente islámico.

Se puso asi fin a esta edición, cuando ya se está preparando la siguiente que tendrá lugar en octubre y versará sobre Arte y Arquitectura en las Catedrales de Castilla y León (www.fundacioncst.com)

Isabel López Fernández

Universidad de Salamanca

Ignacio Hernández

Fundación Cultural Santa Teresa

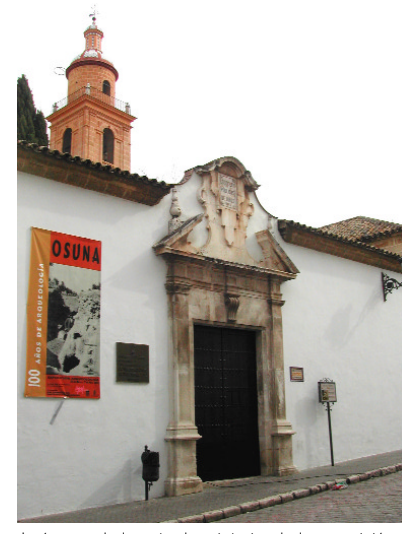

Imágenes de la entrada e interior de la exposición

\section{Osuna conmemora el centenario de las excavaciones de Engel y Paris con una muestra fotográfica}

Osuna expone desde el pasado 25 de marzo la muestra fotográfica "Osuna. 100 Años de Arqueología", organizada por la Escuela Universitaria de Osuna -en colaboración con la Universidad Autónoma de Madrid y el Ayuntamiento de la localidad sevillana- dentro de los actos conmemorativos del centenario de la excavación arqueológica que los franceses Arthur Engel y Pierre Paris desarrollaron en la antigua Urso durante el año 1903.

La muestra fotográfica, de la que ha sido comisario el profesor de la Universidad Autónoma de Madrid Juan Blánquez, se articula en torno a dos ejes básicos cuyos hilos conductores son la fotografía de principios del siglo XX y las nuevas tecnologías respectivamente. El primero comienza con un contexto general de la época y de los albores de la arqueología "ibérica" a finales del siglo XIX y comienzos del XX con lugares representativos como el Cerro de los Santos o personajes como Jorge Bonsor. A continuación pasa a centrarse en los trabajos de la misión arqueológica francesa de 1903 y en los Re- lieves de Osuna. El segundo muestra cómo las nuevas tecnologías ayudan a la arqueología a profundizar en nuestros conocimientos con ejemplos prácticos sobre la cultura ibérica.

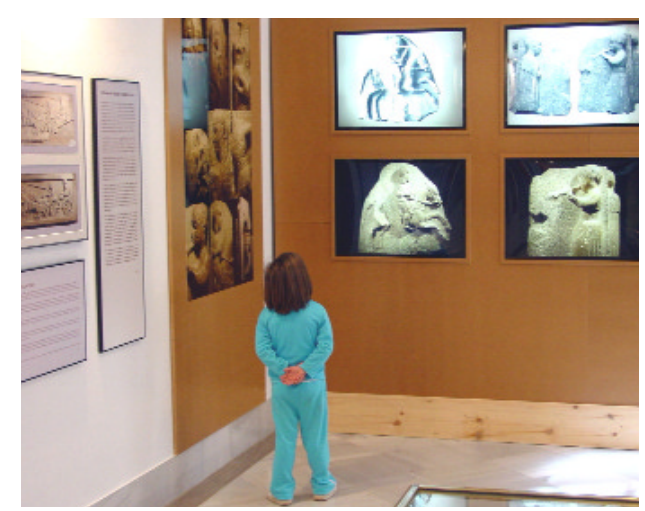

José Ildefonso Ruiz Cecilia Ayuntamiento de Osuna 